\title{
O discurso das tribos urbanas no espaço escolar: categoria, metáfora ou efeito metafórico?
}

\author{
Ana Paula Moreira dos Santos ${ }^{1}$ \\ Universidade do Estado de Mato Grosso
}

Urban tribes: category, metaphor or metaphorical effects?

\begin{abstract}
- RESUMO: Este trabalho tem como finalidade apresentar o resultado parcial de uma proposta de intervenção realizada no $9^{\circ}$ ano do ensino fundamental da escola estadual Presidente Médici, em Cuiabá (MT). Pensamos a constituição dos sentidos e dos sujeitos nas tribos, pela linguagem na narratividade urbana. A proposta, ancorada na análise de discurso de linha francesa, objetivou confrontar-se com o real das tribos urbanas, pela compreensão do modo como a cidade e seus grupos, enquanto espaço simbólico produzem sentidos. O outro objetivo era compreender a relação sujeito, história e espaço urbano, constitutiva do processo de significação destas tribos a partir de materialidades significantes (como vídeos, manchetes de notícias, propagandas, entre outros). Pretendeu-se construir com os alunos um estudo diferente, colocando o olhar em movimento e compreendendo como as noções do "eu urbano" e do "eu grupo" estão relacionadas ao recorte tribos urbanas que podem ser silenciadas, negadas, metaforizadas ou vislumbradas como possíveis sentidos da cidade. Dessa forma, para ressignificar a vivência dos alunos, tratamos as materialidades de tribos urbanas, incluindo as próprias experiências e vivências dos alunos, considerando o equívoco, a ideologia, enfim, os deslizamentos, os efeitos metafóricos nos gestos de interpretação.
\end{abstract}

- PALAVRAS-CHAVE: Tribos urbanas. Análise de discurso. Efeito metafórico.

- ABSTRACT: This paper aims to present a proposal for intervention carried out in the 9th year of elementary school of the state school Presidente Médici, in Cuiabá (MT). We considered the constitution of the senses and the subjects in the tribes, by the language in the urban narrativity. The proposal, anchored in the analysis of French line discourse, aimed to confront the real of the urban tribes, understanding how the city, as a symbolic space produce meanings. The other idea was to understand the relation subject, history and urban space, constitutive of the process of meaning of these tribes from significant materialities (such as videos, news headlines, advertisements, among others). It was intended to construct with the students a different study, putting the gaze in motion and understanding how the notions of the "urban self" and the "Me group" are related to the cut urban tribes that can be silenced, denied, metaphorized or glimpsed possibles senses city. Thus, in order to resignificate the students' experience, we treat the materialities of urban tribes, including their own experiences and experiences, considering the misunderstanding, the ideology, in the end, the slides, the metaphorical effects in the gestures of interpretation.

- KEYWORDS: Urban tribes. Discourse analysis. Metaphorical effect.

\section{Introdução}

Este trabalho apresenta parte do resultado de uma intervenção de dissertação desenvolvida na escola estadual Presidente Médici (Cuiabá/MT), com o objetivo de obtenção do título de mestre, cujo programa é ofertado pela Universidade Estadual do Mato Grosso - Unemat- Mestrado Profissional em Letras. A proposição, de cunho teórico-metodológico, nasce do desejo de que alunos experimentem novos gestos de

\footnotetext{
${ }^{1}$ Mestranda em Linguística pela UNEMAT. annamorsantos@hotmail.com
} 
interpretação, de leitura e escrita, pelo saber urbano. A temática escolhida para esta intervenção, após análise e discussão com os estudantes, constitui algo próprio do espaço urbano, parte do processo de identificação do jovem: as tribos urbanas. Nesta proposta, o espaço significante da cidade é evidenciado. $\mathrm{O}$ aluno se compreendendo em diferentes posições-sujeito, olha de outro modo para os deslocamentos da língua na/da cidade. Nos discursos das tribos urbanas percebe-se o funcionamento da língua, seus deslizamentos e apagamentos, permitindo que os alunos avancem da mera classificação e categorização para uma nova possibilidade de interpretação pelo interdiscurso, pelos efeitos metafóricos.

Considerando que a escola nos mostra uma visão de língua e escrita, cuja atividade primeira está centrada na interpretação de textos, com respostas muitas vezes prontas, as definições e orientações em livros, manuais didáticos e documentos oficiais que orientam o fazer pedagógico podem encaminhar as atividades docentes para um fechamento das reflexões, ou ainda podem determinar os sentidos atribuídos à prática pedagógica. Estas práticas podem impossibilitar avanços na relação sujeito, sentido e espaço, tratando o texto (escrito ou oral) analisado em sua superficialidade (não como discurso). Orlandi (1998, p. 14) aponta "por isso temos proposto que se considere o texto, em sua materialidade, como uma 'peça' com suas articulações, todas elas relevantes para a construção do ou dos sentidos." O texto é, portanto, discurso, como uma palavra em movimento, prática de linguagem. E a escola, muitas vezes, tem apresentado o discurso como transparente, tendo um sentido único e não como uma intervenção capaz de fazer o homem significar.

\begin{abstract}
A escola não tem que se moldar ao "urbano", mas ir para o espaço da cidade enquanto real histórico muitas vezes apagado pelo urbanístico. Deve confrontar-se com o real da rua com seus sujeitos, seus modos de existência, de resistência e de saber, de arte, de cultura. Que não é a letrada, mas é, existe em suas formas outras (ORLANDI, 2004, p. 153).
\end{abstract}

Pensar discursivamente, a partir de diversas proposições, a dinamicidade da língua e como estes grupos contemporâneos se articulam e significam na cidade é uma possibilidade de ressignificação da prática escolar. Cada tribo, cada agrupamento nas ruas, praças e espaços da cidade produz novos sentidos. E por que este saber urbano é silenciado pela escola e apagado nos instrumentos linguísticos mais convencionais, como nos dicionários, livros didáticos, notícias, reportagens, textos verbais e não verbais? Diversas vezes os próprios professores de língua portuguesa não reconhecem como "legítimo" o saber urbano das ruas e silenciam as vozes que ecoam nos corredores, intervalos e momentos de descontração da escola, o que os alunos experimentam e/ou veem diariamente nas praças, ruas e outros espaços da cidade. O que soa diferente e estranho para a instituição escolar é o que, na nossa intervenção, faz parte da ampliação de gestos de interpretação, aquilo que se evidencia no modo de vestir e circular destes grupos, a linguagem corporal, as gírias, neologismos. O aparelho escolar, como parte da aparelhagem do estado, segue o institucionalizado, aquilo que conduz à homogeneização dos sujeitos, momento em que a figura do professor orienta os resultados esperados para todos os alunos.

Por mais que os programas educativos "modernos" falem em criar um hábito de leitura, respeitando o aluno na sua relação individual com o texto, sabemos, pelo modo como a maioria das aulas são conduzidas e pelo modo da maior parte das avaliações, que a história individual de leitura - a relação específica com o texto, com a sedimentação dos sentidos e a intertextualidade - não entra no jogo das relações professor-aluno. É claro que ela entra em 
jogo na relação aluno-professor-texto, mas frequentemente anula-se est funcionamento na prática educacional, homogeneizando a leitura e a escrita. (PFEIFFER, 1995, p.78)

Sendo assim, para nos distanciarmos desta prática homogeneizante desenvolvemos uma metodologia que consiste em diferentes atividades de leitura com textos em distintas materialidades - verbetes de dicionários, tirinhas, narrativas, propagandas, entrevistas - que abordam a temática, estimuladas por conversas e formulação de verbetes para o dicionário InFormal online, por meio dos quais questionamos a posição sujeito cidadão e suas identificações no espaço urbano. Destacamos a importância do dispositivo teórico que sustentou o desenvolvimento da proposta pela análise de discurso francesa, que facilitou aos alunos a compreensão dos deslizamentos, das condições de produção dos discursos, enfim que os sentidos sempre podem ser outros.

\section{A Análise de Discurso e a instituição escolar}

A proposição foi desenvolvida no período de quatro meses em uma turma de $9^{\circ}$ ano da escola estadual Presidente Médici, cujo histórico aponta para alunos de difícil comportamento e com poucos avanços na aprendizagem. Na minha escuta como analista e após conversas com os alunos procuramos construir um dispositivo de interpretação para melhorar os mecanismos e limites da leitura. Não há verdade oculta: há opacidade, equívoco nos objetos simbólicos. A nossa interpretação é apenas uma dentre infinitas possibilidades e não esgotamos o objetivo em uma descrição/interpretação.

Considerando que nosso objeto é o saber urbano (particularmente das tribos urbanas dos municípios de Cuiabá e Várzea Grande, Mato Grosso) procuramos compreender os processos de interpretação, de produção de sentidos das tribos urbanas mobilizando a teoria da Análise do Discurso (doravante AD). Sob essa perspectiva abordamos os processos de significação do urbano pela linguagem, pela ideologia, entendendo o discurso como efeito de sentido entre interlocutores. A AD, formulada a partir dos trabalhos de Michel Pêcheux na França e de Eni Orlandi no Brasil, contribui, de forma relevante, para que novos sentidos sejam associados às relações com a escrita e a leitura, como práticas de linguagem.

\footnotetext{
A AD nos permite ver o ensino como prática política e a linguagem como materialidade significante opaca, equívoca e incompleta. Por isso, o professor precisa estar atento para questionar a literalidade e os efeitos de verdade produzidos pelos manuais didáticos. (FERNANDES, 2015, p.184).
}

A tarefa é mostrar, portanto, que os sujeitos ali inscritos podem gerar sentidos diversos, compreendendo, assim, que ler é atribuir um sentido em meio a outros também possíveis. Estes deslocamentos permitem novas formulações dos alunos a respeito de que língua se fala e qual é a que se escreve, considerando que no imaginário dos alunos a língua portuguesa está no dicionário, na gramática, nos livros didáticos e não é a mesma que se fala. Assim nasce uma relação tensa, contraditória, entre língua fluida e imaginária, conforme distinção proposta por Orlandi (2002), para quem a língua imaginária é aquela institucionalizada, das normas, dos registros formais, que fixa e sistematiza a língua num sistema. De acordo com esta noção, o sujeito acredita que o que está gramaticalizado é inalcançável, não é a língua de suas experiências cotidianas, 
por estar inscrito nos movimentos e deslizamentos dos discursos, na língua fluida. Nos dizeres de Orlandi:

Defini a língua imaginária como sistema fechado, normas, artefato do linguista (mas também dos missionários e outros assemelhados) ao passo que a língua fluida é a língua no mundo, sem regras que a aprisionem, língua no acontecimento do significar na relação de homens com homens, sujeitos e sujeitos (ORLANDI, 2002, p.13).

A escola e os instrumentos linguísticos constroem um saber sobre a língua imaginária, que são as normas. A língua fluida é aquela que encontra lugar nas relações cotidianas dos sujeitos. Como para nós, analistas de discurso, não existe só uma língua, mas várias, pensamos que a sala de aula seja um espaço de produção e construção de conhecimentos sobre a língua. É também um espaço que possibilita a desconstrução deste dizer institucionalizado (professor autoriza e controla processos), característica do discurso pedagógico, autoritário, o qual abordaremos mais adiante.

Podemos dizer que o lugar a partir do qual fala o sujeito é constitutivo do que ele diz. Assim se o sujeito fala a partir do lugar de professor, suas palavras significam de modo diferente do que se falasse do lugar de aluno. [...] Como nossa sociedade é constituída por relações hierarquizadas, são relações de força, sustentadas no poder desses diferentes lugares, que se fazem valer na comunicação". A fala do professor vale (significa) mais do que a do aluno. (IBIDEM,p.39-40)

A temática do discurso das tribos urbanas procura investir mais poder à voz dos alunos no processo de análise dos sentidos, pois considera o processo de identificação dos jovens na posição-sujeito citadinos, pedestres, partícipes de diversos grupos urbanos. Devemos, para isto, mobilizar saberes sobre a língua na cidade (como espaço simbólico), por meio de práticas de linguagem que levem em conta diversas materialidades significantes como vídeos, filmes, fotografias, notícias, vestimentas, acessórios etc. Sobre isso, Orlandi diz:

[...] todo o processo de produção de sentido se constitui de uma materialidade que lhe é própria. Assim, a significância não se estabelece na indiferença dos materiais que a constituem, ao contrário, é na prática material significante que os sentidos se atualizam, ganham corpo, significado particularmente (ORLANDI, 1995, p. 35).

Em nosso trabalho analisaremos a narratividade urbana, que não tem um único narrador, mas muitos inscritos nas vivências de flagrantes, na tatuagem, pelo esporte urbano, skatistas, bikers, corredores, nos grafites, nas pichações, pelos emos, pelos nerds, pelos rappers. As manifestações e passeatas. A instituição escolar pode mobilizar os alunos em direção à produção de sentidos destes grupos, suas artes, seus escritos, desconstruindo preconceitos e buscando compreender pelo funcionamento da linguagem e suas condições de produção a multiplicidade de sentidos em torno do tema. Em "Cidade dos Sentidos", Orlandi menciona:

Por seu lado, a sociedade como um todo se movimenta e há uma mudança nas formas tradicionais de comunicação, mudança que as escolas não estão percebendo ou dando atenção ou mesmo atendendo. Desse modo a escola não vai para a rua, não se abre, privilegia formas tradicionais e não dá acesso às outras formas que estão se gestando para saber o que fazer com elas, para que elas tomem suas formas, para dar-lhes seu futuro, elaborando sentidos antes não existentes, não realizados (ORLANDI, 2004, p.113). 
Concebida dessa maneira, esta proposta objetiva ver e ler o que está neste lugar, além dos muros da escola, procurando pensar os grupos que se movimentam dentro e fora deste espaço, que também se conhecem pela interatividade da tecnologia e se unem por interesses comuns.

Para Michel Maffesoli (1998), em sua obra $O$ tempo das tribos, as tribos urbanas podem ser pensadas como massas de sujeitos que se agregam em comunidades emocionais temporárias, em busca de processos de identificação, de novos paradigmas.

Maffesoli (ibidem) mobiliza a noção de neotribalismo, que não deixa perder a origem e constituição da antiga noção de tribalismo que temos nos tempos primórdios, mas que hoje se constituem de modos diversos, pelas condições de produção do tempo atual. De qualquer maneira os agrupamentos ocorrem, de modo geral, pela inscrição territorial e pelo que denomina de cimento emocional.

Qualquer que seja, no caso, o território em questão ou o conteúdo da afeição: interesses culturais, gostos sexuais, cuidados vestimentares, representações religiosas, motivações intelectuais, engajamentos políticos. Podemos multiplicar, à vontade, os fatores de agregação, mas por outro lado, eles estão circunscritos a partir destes dois pólos que são o espaço e o símbolo (partilha, forma específica de solidariedade, etc). Isso é o que melhor caracteriza a intensa atividade comunicacional que de múltiplas maneiras serve de nutriente ao que chamo de neotribalismo. (MAFFESOLI, 1998, p. 186)

Os sentidos são determinados pelas condições de produção e pelos sujeitos interpelados pela ideologia ao se inscreverem no espaço urbano em diferentes posições sujeito. $\mathrm{Na}$ relação com objetos simbólicos e com o espaço caracteriza-se o acontecimento urbano e novos gestos de significação são associados. $\mathrm{O}$ aluno, vestido de uniforme, dentro do espaço escolar se significa e significa a cidade diferente ao se deslocar como punk a caminho de encontrar sua tribo na praça da cidade.

\footnotetext{
Num espaço (habitado) de memória, de subjetividades, a história se formula na noção de "eu" urbano. Esse sujeito, por sua vez, como está produzindo sentidos na cidade - textualizando sua relação com objetos simbólicos nesse mundo particular do urbano - vai produzir uma realidade que é estruturada de tal maneira que vai nos dar, enquanto analistas, uma imagem de texto, do acontecimento urbano, que é histórica e que se apresenta em seus vestígios. (ORLANDI, 2004, p. 28)
}

Assim é dada a importância da escola trazer esses discursos, da globalização, da mundialização, do neotribalismo para discussão, sem esquecer-se do discurso da subjetividade, do processo de identificação do jovem como sujeito histórico e simbólico, compreendendo a metaforização dos movimentos sociais urbanos.

\section{Tribos urbanas: categorias ou efeitos metafóricos?}

A proposição dessa temática possibilitou aos alunos estudarem além da categorização, da mera classificação de expressões, que fecha o sentido em uma univocidade e deixa transparente os sentidos. Os gestos de interpretação acontecem em todas as manifestações da linguagem e pelo processo discursivo amplia-se o propósito da prática educacional: o crescente domínio das relações complexas que a linguagem nos permite compreender, a explicitação dos sentidos e suas relações. Para a $\mathrm{AD}$, não há sentido sem interpretação. E não há sentido sem metáfora. Os sentidos existem 
exclusivamente pelas relações de metáfora, realizadas através de paráfrases, substituições e formações de sinônimos.

Nessa medida, buscamos ir além da mera decodificação para que pudessem articular os sentidos produzidos nas leituras de diferentes materialidades, como diz Orlandi "é essa articulação que deveria ser explorada no ensino da leitura, quando temos como objetivo trabalhar a capacidade de compreensão do aluno" (1988, p.40).

Vale lembrar, que as atividades desenvolvidas nas aulas de Língua Portuguesa foram elaboradas de modo a possibilitar ao aluno uma nova forma de pensar que o levasse a sair da superficialidade da língua para a efetivação do processo discursivo.

Um dos trabalhos consistiu em uma atividade oral desenvolvida com os alunos para que manifestassem o que entendiam por "tribo". As definições surgiram de forma semelhante apontando para relações com indígenas, aborígenes, como grupos de índios do Brasil. Em sequência, provocamos um confronto de ideias associando a palavra urbana à palavra tribo. Nestas condições, considerando os sentidos, em outros materiais, pudemos constatar que as palavras não têm o mesmo significado, e que os sentidos podem ser outros, mas não qualquer um.

A partir deste momento, distanciando da prática da categorização da expressão para relacionar língua à exterioridade, perguntamos:__Falar de tribo na contemporaneidade é somente remeter-se ao índio? De quais tribos estamos falando? _Devemos considerar que na produção de sentidos há uma relação com o histórico, com as condições de produção da sociedade, naquele determinado espaço e tempo? Por isso trouxemos a investigação de diferentes materialidades.

$\mathrm{Na}$ análise de discurso pêcheutiana surge como questão fundamental as "condições verbais de existência dos objetos (científicos, estéticos, ideológicos...) em uma conjuntura dada" (PÊCHEUX, 2011, p. 152). Assim, assumindo essa posição, explicamos aos alunos que os deslizamentos, as derivas fazem parte da análise.

De acordo com Orlandi (2006, p.32) "É ainda o efeito metafórico, a deriva, o deslizamento de um enunciado em outro, que pode nos fazer compreender o que chamamos historicidade na análise do discurso".

Selecionamos diversas materialidades para o trabalho, a seguir, destacamos uma delas:

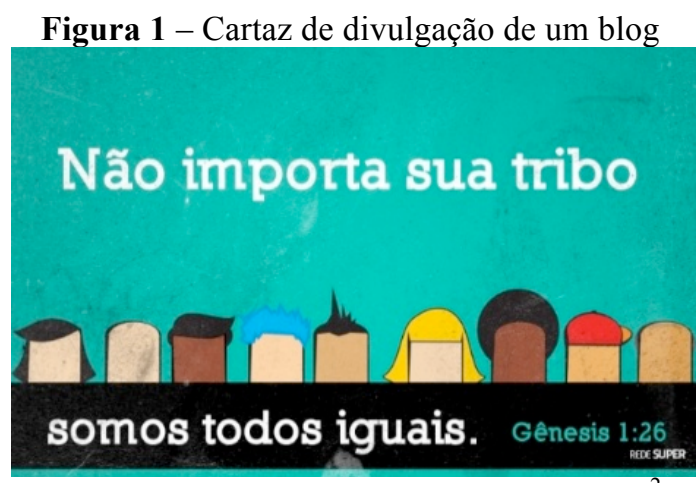

Fonte: Imagem de um site de comunicação ${ }^{2}$

Neste ponto, à medida que os alunos liam o cartaz conversamos a partir da ideia inicial de que tribo remetia ao imaginário de índio. Após leitura mais cuidadosa do cartaz apontaram para a presença de uma formação discursiva religiosa, reconhecendo

\footnotetext{
${ }^{2}$ Disponível em: https://br.pinterest.com/pin/462041242999164092
} 
parte do livro da Bíblia (Gênesis) e identificando a tribo de Judah, citada diversas vezes na Bíblia.

Após novas leituras entenderam que o convite explicita que toda tribo é bemvinda no núcleo religioso e pode não ser necessariamente uma tribo urbana. Aqui há um deslizamento, uma leitura possível: pode ser a família, a igreja, como acontecia nas tribos citadas na Bíblia. Enquanto o enunciado verbal diz "Não importa sua tribo... somos todos iguais", o elemento não verbal explicita a transfiguração do ser humano sem face, de várias raças, estilos, gêneros, faixas-etárias. Ir além da aparência é o que se deseja, sentido do senso comum preconizado por todas as religiões. $\mathrm{O}$ efeito metafórico produzido aqui remete ao sentimento de pertencimento a uma "tribo" e de respeito, porque somos iguais.

Outra materialidade apresentada foi uma imagem do escritor Seth Godin ${ }^{3}$, um autor americano de livros sobre negócios. No livro "Tribos: precisamos que você nos lidere", Seth fala sobre as possibilidades que nos oferece hoje a Web 2.0 para colaborar, criar e conduzir nossa própria "tribo"; ou seja, para liderar uma comunidade de pessoas que pensam como formadores que podem ser geograficamente dispersos, mas estão conectados.

Figura 2 - Livro: Tribos: nós precisamos que você nos lidere

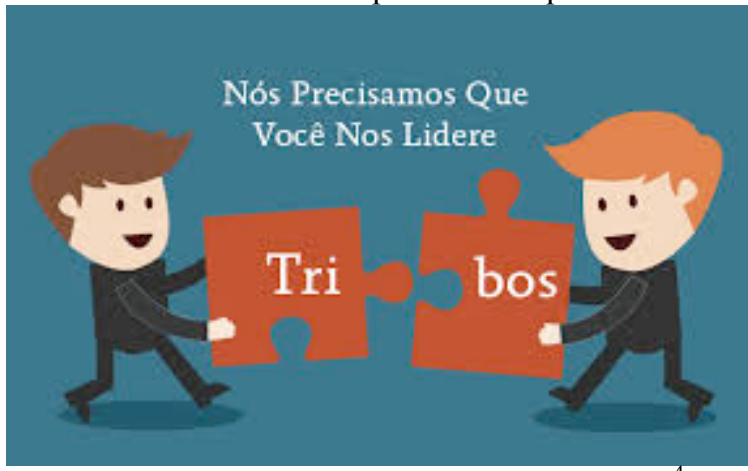

Fonte: Imagem de um site de comunicação

Os alunos citam alguns sentidos produzidos pelas vendas, pelos negócios, o que chamamos de formação discursiva do marketing. As peças do quebra-cabeça ainda estão soltas, mas se há um líder, como em todas as tribos mais antigas, o ambiente colaborativo acontecerá, ou seja, haverá trocas e relações entre os membros que possuem interesses e pensamentos próximos, comuns. O pronome pessoal e o oblíquo NÓS e NOS indicam um chamamento, mas não identificam o dono do chamado. Quem são os "nós"? Sujeitos dispersos pelo espaço urbano, pelas práticas de globalização indicando que todas as tribos têm necessidade de liderança, sentido do imaginário de que toda tribo clama por líderes?

\section{Considerações finais}

A diversidade de textos disponibilizados aos alunos concedeu maior liberdade na produção da leitura, colaborando para a compreensão de que as pessoas não são sujeitos isolados e o ambiente é construído. Os alunos puderam pensar em inferências e opiniões sobre os textos, alterando o esquema reprodutor de leitura, criticado por

\footnotetext{
${ }^{3}$ Seth Godin fundou e foi CEO de uma das primeiras companhias de marketing online, a Yoyodyne, que mais tarde vendeu ao Yahoo!. (www.sethgodin.com.br)

${ }^{4}$ Disponível em : http://www.jogaojob.com.br/resenha-tribos-nos-precisamos-que-voce-nos-lidere/
} 
Orlandi (1988), por estruturar um modelo de leitura a ser seguido, que privilegia a autoridade x. A abordagem mais comum nas escolas desconsidera o caráter sóciohistórico e solicita ao aluno que repita modelos e olhe para o texto como unidade fechada em si mesma, onde estão todas as respostas. Dessa forma, quando o material de leitura questiona o que o "autor quis dizer" não rompemos o ciclo de trabalho apenas com evidências.

Na perspectiva aqui considerada, foi possível saber sobre a estabilidade de uns sentidos e não estabilidade de outros. Com isso possível promover deslocamentos dentro da conjuntura estabelecida e a partir de condições de produção específicas, obter resultados diferentes. Isso equivale a dizer que é possível problematizar as práticas de leitura e escrita dentro do espaço escolar fazendo com que haja um deslocamento dentro do Discurso Pedagógico, saindo do tipo Autoritário que impede que os alunos assumam a função-autor nas atividades realizadas na escola.

É importante ressaltar que o desenvolvimento desta proposta permitiu-nos refletir em novas condições de produção, com outros sujeitos, outras histórias, enfim, fez-nos compreender os dizeres de Orlandi "que o sentido sempre pode ser outro".

\section{REFERÊNCIAS}

ORLANDI, Eni P. Análise de discurso: princípios e procedimentos. 7 ed. Campinas: Pontes, 1999

Discurso e leitura. 9.ed. São Paulo: Cortez, 1999.

Interpretação: autoria, leitura e efeitos do trabalho simbólico. $2^{\mathrm{a}}$ ed. Petrópolis, RJ: Editora Vozes, 1998.

Cidade dos Sentidos. Campinas, SP. Pontes, 2004

FERNANDES, Carolina. Entre o ver e o ler: gestos de leitura da materialidade visual implicando outros gestos de ensino. Gestos de Leitura. Campinas, SP. Unicamp, 2015.

MAFESOLLI, Michel. O tempo das tribos: o declínio do individualismo nas sociedades de massa. Tradução de Maria de Lourdes Menezes. RJ: Forense Universitária, 1998.

PECHEUX, Michel. Semântica e discurso: uma crítica à afirmação do óbvio. Tradução de Eni Puccinelli Orlandi et al. SP: Editora Unicamp, 2014.

PFEIFFER, Cláudia R. C., Que autor é este? .1995. 146 f. Tese (Doutorado em Linguística) - Universidade Estadual de Campinas.

Recebido em: junho de 2017.

Aprovado em: julho de 2017.

Como citar este trabalho:

SANTOS, A. P. M. dos. O discurso das tribos urbanas no espaço escolar: categoria, metáfora ou efeito metafórico? Traços de linguagem, v. 1, n. 1, p. 20-27, 2017. 